\title{
The Effect of Quetiapine and Olanzapine on Thyroid Function in Schizophrenic Patients
}

\author{
Ola H Samawi ${ }^{*}$, Rawan M AlDabbas, Toleen I Bisharat, Bayan A Aldowaib, Farah A AlAdayleh
}

\author{
The Royal Medical Services. Amman/Jordan
}

DOI: $\underline{10.36347 / \text { sajp.2020.v09i05.003 }}$

| Received: 14.02.2020 | Accepted: 21.02.2020 | Published: 30.05.2020

*Corresponding author: Ola H Samawi

\section{Abstract}

Background: Thyroid function abnormalities are relatively common in patients with schizophrenic disorders due to the medical management of the disease with antipsychotic drugs which causes abnormalities in thyroid gland parameters. Objective: The purpose of this study is to explore effect of Quetiapine and Olanzapine on thyroid function tests in a number of schizophrenic patients and to compare the impact of these antipsychotic drugs on thyroid function. Patients and method: A retrospective cross sectional observational study. One hundred and six patients involved in this study allocated into three study arms. Thyroid data, consisting of values for thyroid-stimulating hormone (TSH), total triiodothyronine (TT3), and total thyroxine (TT4) were obtained at baseline and after 12 weeks of treatment through Hakeem Data base. To evaluate differences in TT3, TT4 and TSH concentrations in patients before and after treatment versus control group, one-way ANOVA and unpaired t-tests were used. Values less or equal to 0.05 were considered significant. Results: Drug treatment in schizophrenic patients was associated with decrease of TT3 and TT4 ( $\mathrm{p}<0.05)$ and with elevation of TSH $(\mathrm{p}=0.05)$ in both study arms in comparison with the control arm and with baseline data. Conclusion: This study shows that 3 months therapy with quetiapine and olanzapine leads to a abnormalities in thyroid function parameters of schizophrenic patients.

Keywords: Quetiapine Olanzapine Thyroid Schizophrenic.

Copyright @ 2020: This is an open-access article distributed under the terms of the Creative Commons Attribution license which permits unrestricted use, distribution, and reproduction in any medium for non-commercial use (NonCommercial, or CC-BY-NC) provided the original author and source are credited.

\section{INTRODUCTION}

Schizophrenia is a chronic and complex psychiatric illness that influences the thinking process, the behavior, and the feelings in affected persons. Individuals suffering from schizophrenic disorders might appear such they have missed feeling with truth. Even though schizophrenic disorder is not as public as other psychological illnesses, the complications may lead to disability [1].

Schizophrenia appears with incidents of central disfigurement of intellectuality and awareness in addition to unfitting cognition. The clinical presentations include hallucinations, delusions, abnormal motor behavior cognitive impairment and poverty in natural way of speaking. Classically, the beginning of the illness happens in late puberty, displaying with an incidents of mainly positive symptoms [2].

Negative clinical features are problematic to be identified but are related with more morbidity rate since they distract the person's feelings and performance. The most prevalent negative symptoms are depression, terminated emotive communication, manic mood, poor attention and "avolition". It is vital to recognize that negative symptoms may be either principal to a conclusion of suffering from schizophrenic disorder or secondary to associated mental illness, drugs, or ecological reason [3].

The pathophysiology of schizophrenia is unidentified at present. Impairments of the neurotransmitters "serotonin", "noradrenaline", and "dopamine" at their receptors may have a part in the development of schizophrenia. Also, white matter ischemia in various zones in the brainstem are allied with appearance this mental illness [4].

Management of schizophrenia includes therapeutic drugs and psychotherapy. Psychotherapy methods are categorized into 3 groups: individual, group, and cognitive behavioral. Regarding pharmacotherapy, numerous medicines are applied to manage schizophrenia [5]. Drug choice is influenced by the presence of depression or mania. Primary 
management using drugs alongside with respectable premorbid function frequently leads to successful results. When depression is present, combinations of antidepressants like "sertraline" or "fluoxetine" with an antipsychotic like "haloperidol" or "olanzapine" are used. If mania is present, using mood stabilizers like "lithium" or "carbamazepine with an antipsychotic are practiced [6]. Drugs include antipsychotic agents like "haloperidol", "risperidone", "paliperidone", "olanzapine", "clozapine", "ziprasidone" and "aripiprazole". Anti-manic drugs used in the treatment of schizophrenia are lithium and carbamazepine. In the management of depressive symptom in schizophrenic patients "selective serotonin reuptake inhibitors (SSRIs)" are favored over other antidepressant classes. This class of drugs includes "fluoxetine", "sertraline", "paroxetine", "fluvoxamine", "citalopram", and "escitalopram" [7].

The impairments in thyroid function in individuals with schizophrenia are well reported in clinical trials and case reports in the last two decades. Dopamine releases within the circulation is recognized to prevent the stimulatory actions of thyroid-releasing hormone (TRH), and any agent with dopaminergic activity can block thyroid stimulating hormone (TSH) release [8]. Therefore, management of individuals with classical antipsychotics may result in alteration in thyroid test according to on medications' pharmacologic profile and dopaminergic activity. Recent researches and case studies have revealed abnormalities in thyroid function in patients on quetiapine or olanzapine which may necessitate cessation or start of thyroid replacement drugs [10].

The purpose of this study is to explore effect of Quetiapine and Olanzapine on thyroid function tests in a number of schizophrenic patients and to compare the impact of these antipsychotic drugs on thyroid function.

\section{PATIENTS AND METHOD}

A retrospective cross sectional observational study was conducted at King Hussein medical center (KHMC) after obtaining ethical approval from the ethical committee of the Royal Medical Services (RMS). Schizophrenic patients without a history of thyroid treatment or antipsychotic drug, who are managed with quetiapine or olanzapine in doses, ranged between 200to $400 \mathrm{mg}$ daily and 5-10 $\mathrm{mg}$ respectively was involved in the study. Healthy individual participated in the study as a control group. Data form schizophrenic patients was collected from psychiatry clinic in KHMC. Thyroid data, consisting of values for thyroid-stimulating hormone (TSH), total triiodothyronine (TT3), and total thyroxine (TT4) was evaluated. Patient's clinical information was accessed through Hakeem Data base. Readings of patient's thyroid data was recorded before and after 3 months of therapy. To evaluate differences in TT3, TT4 and TSH concentrations in patients before and after treatment versus control group, one-way ANOVA and unpaired ttests was used. Values less or equal to 0.05 were considered to be significant.

\section{RESULTS}

One hundred and six Schizophrenic patients in the age from 26 to 56 years old were involved in the study. The study sample was divided into 3 Arms: 32 patients (20 males and 12 females) on Olanzapine, 36 patients on Quetiapine (27 males and 9 females). The third arm consists 38 healthy individuals. Sociodemographic characteristics and baseline levels of $\mathrm{TSH}, \mathrm{tT} 3$ and tT4 of the three study arms are illustrated in table and Table 2 respectively.

Table-1: Characteristics of patients in the three study arms

\begin{tabular}{|c|c|c|c|c|}
\hline Variable & $\begin{array}{c}\text { Olanzapine } \\
\mathbf{N = 3 2} \\
(\mathbf{m e a n} \pm \mathbf{S D})\end{array}$ & $\begin{array}{c}\text { Quetiapine } \\
\mathbf{N = 3 6} \\
(\mathbf{m e a n} \pm \mathbf{S D})\end{array}$ & $\begin{array}{c}\text { Control } \\
\mathbf{N = 3 8} \\
(\mathbf{m e a n} \pm \text { SD) }\end{array}$ & P value \\
\hline Age & $41.22 \pm 9.4$ & $39.45 \pm 9.11$ & $43.56 \pm 10.09$ & 0.834 \\
\hline BMI category & $3(9.3 \%)$ & $5(14.2 \%)$ & $5(13.1 \%)$ & 0.711 \\
Underweight & $14(43.7 \%)$ & $12(33.3 \%)$ & $12(31.5 \%)$ & \\
Normal & $6(18.7 \%)$ & $5(13.8 \%)$ & $5(13.1 \%)$ & \\
Overweight & $3(9.3 \%)$ & $8(22.2 \%)$ & $9(23.8 \%)$ & \\
Obese & $6(18.75 \%)$ & $6(16.6 \%)$ & $7(18.4 \%)$ & \\
Morbidly obese & $12(37.5 \%)$ & $9(25 \%)$ & $16(42.1 \%)$ & \\
\hline Gender & $20(62.5 \%)$ & $27(75 \%)$ & $22(57.9 \%)$ & \\
Female & & & \\
Male &
\end{tabular}

Table-2: Baseline levels of TSH, TT3 and TT4 of the three study arms

\begin{tabular}{|c|c|c|c|c|}
\hline Variable & $\begin{array}{c}\text { Olanzapine } \\
\mathbf{N = 3 2} \\
(\mathbf{m e a n} \pm \mathbf{S D})\end{array}$ & $\begin{array}{c}\text { Quetiapine } \\
\mathbf{N = 3 6} \\
(\mathbf{m e a n} \pm \mathbf{S D})\end{array}$ & $\begin{array}{c}\text { Control } \\
\mathbf{N = 3 8} \\
(\mathbf{m e a n} \pm \mathbf{S D})\end{array}$ & P value \\
\hline TT3 $(\mathbf{n g} / \mathbf{m l})$ & $1.26 \pm 0.21$ & $1.31 \pm 0.34$ & $1.09 \pm 0.28$ & 0.0811 \\
\hline TT4 $(\mathbf{m c g} / \mathbf{d L})$ & $8.09 \pm 1.87$ & $7.99 \pm 1.85$ & $8.01 \pm 1.42$ & 0.094 \\
\hline TSH $(\mathbf{m I U} / \mathbf{L})$ & $1.55 \pm 1.21$ & $1.41 \pm 0.89$ & $1.43 \pm 0.91$ & 0.075 \\
\hline
\end{tabular}


In olanzapine arm, there were no significant changes in found TT3 levels when compared with the baseline levels and with the control arm, whereas significant changes had occurred in TT4 and TSH levels. In quetiapine arm, significant changes were seen in TT3, TT4 and TSH levels after 12 weeks when compared with the baseline level and with the control group as shown in table 3 .

Table-3: Changes in levels of TSH, TT3 and TT4 after 12 weeks of treatment

\begin{tabular}{|c|c|c|c|}
\hline Variable & $\begin{array}{c}\text { Olanzapine } \\
\mathrm{N}=32 \\
(\text { mean } \pm \text { SD) } \\
\end{array}$ & $\begin{array}{c}\text { Quetiapine } \\
\begin{array}{c}\mathrm{N}=36 \\
(\mathrm{mean} \pm \mathrm{SD})\end{array}\end{array}$ & $\begin{array}{c}\text { P value } \\
\text { Between the treatment } \\
\text { arms }\end{array}$ \\
\hline $\begin{array}{l}\text { TT3 (ng/ml) } \\
\text { Baseline } \\
\text { After } 12 \text { weeks }\end{array}$ & $\begin{array}{c}1.26 \pm 0.21 \\
1.19 \pm 0.20\end{array}$ & $\begin{array}{c}1.31 \pm 0.34 \\
1.108 \pm 0.15\end{array}$ & 0.0432 \\
\hline P-value with baseline & 0.0711 & 0.041 & 0.031 \\
\hline P-value with control arm & 0.0832 & 0.021 & 0.015 \\
\hline $\begin{array}{l}\text { TT4 (mcg/dL) } \\
\text { Baseline } \\
\text { After } 12 \text { weeks }\end{array}$ & $\begin{array}{c}8.09 \pm 1.87 \\
6.91 \pm 1.72\end{array}$ & $\begin{array}{c}7.99 \pm 1.85 \\
7.32 \pm 1.94\end{array}$ & 0.039 \\
\hline P-value with baseline & 0.039 & 0.02 & 0.025 \\
\hline P-value with control arm & 0.021 & 0.035 & 0.032 \\
\hline $\begin{array}{l}\text { TSH }(\mathrm{mIU} / \mathrm{L}) \\
\text { Baseline } \\
\text { After } 12 \text { weeks }\end{array}$ & $\begin{array}{c}1.55 \pm 1.21 \\
2.43 \pm 1.45\end{array}$ & $\begin{array}{c}1.41 \pm 0.89 \\
1.494 \pm 2.01\end{array}$ & 0.028 \\
\hline P-value with baseline & 0.001 & 0.001 & 0.001 \\
\hline P-value with control arm & 0.001 & 0.001 & 0.001 \\
\hline
\end{tabular}

\section{DISCUSSION}

The relation between thyroid hormone and schizophrenic disorder is well documented. In the current study, there was no any abnormality in any thyroid parameter at baseline [11]. This is consistent with a previous study which indicated that schizophrenic individuals are not suffering from thyroid gland abnormality. Actually, many clinical trials and case studies have screened thyroid function tests in schizophrenic individuals revealing various alterations [12]. Our findings showed that thyroid alteration from baseline and after 12 weeks of treatment with quetiapine and olanzapine. There were significant changes all thyroid testing parameters at the end of the study except for TT3 in the olanzapine arm. Quetiapine is well documented to exert side effects on thyroid function. In many studies, approximately $12 \%$ of individuals managed with quetiapine suffered from thyroid abnormalities [13]. In a recent study, thyroid function was measured in 44 schizophrenic individuals after eight weeks of treatment with quetiapine. They had reports a significant abnormality in thyroid parameters levels which is consistent with our study. The explanation for the reduction in TT4 levels in quetiapine study arm could be linked to competitive metabolism of thyroid hormones and quetiapine by liver enzymes.

\section{CONCLUSION}

This study shows that 3 months therapy with quetiapine and olanzapine leads to a abnormalities in thyroid function parameters of schizophrenic patients.

\section{REFERENCES}

1. Arango C, Robles O, Parellada M, Fraguas D, Ruiz-Sancho A, Medina O, Zabala A, Bombín I, Moreno D. Olanzapine compared to quetiapine in adolescents with a first psychotic episode. European child \& adolescent psychiatry. 2009 Jul $1 ; 18(7): 418$.

2. Vitiello B, Correll C, van Zwieten-Boot B, Zuddas A, Parellada M, Arango C. Antipsychotics in children and adolescents: increasing use, evidence for efficacy and safety concerns. European Neuropsychopharmacology. 2009 Sep 1;19(9):62935.

3. Arvanitis LA, Miller BG. Multiple fixed doses of "Seroquel"(quetiapine) in patients with acute exacerbation of schizophrenia: a comparison with haloperidol and placebo. Biological psychiatry. 1997 Aug 15;42(4):233-46.

4. Thanoon IA, Mahmood IH, Ibrahim A. Effects of quetiapine on thyroid function tests in schizophrenic patients. Tikrit J. Pharm. Sci. 2011;7(1):90-4.

5. Kontaxakis VP, Karaiskos D, Havaki-Kontaxaki BJ, Ferentinos P, Papadimitriou GN. Can quetiapine-induced hypothyroidism be reversible without quetiapine discontinuation?. Clinical neuropharmacology. 2009 Sep 1;32(5):295-6.

6. Goren JL, Levin GM. Quetiapine, an atypical antipsychotic. Pharmacotherapy: The Journal of Human Pharmacology and Drug Therapy. 1998 Nov 12;18(6):1183-94.

7. Bunevicius R, Steibliene V, Prange AJ. Thyroid axis function after in-patient treatment of acute 
psychosis with antipsychotics: a naturalistic study. BMC psychiatry. 2014 Dec 1;14(1):279.

8. Lindberg N, Virkkunen M, Tani P, Appelberg B, Virkkala J, Rimon R, Porkka-Heiskanen T. Effect of a single-dose of olanzapine on sleep in healthy females and males. International clinical psychopharmacology. 2002 Jul 1;17(4):177-84.

9. XU JH, CHEN YP. Schizophrenic patients in the 60 cases of thyroid hormones results is related to the analysis $[\mathrm{J}]$. Medical Journal of Chinese People's Health. 2010;23.

10. Canuso CM, Hanau M, Jhamb KK, Green AI. Olanzapine use in women with antipsychoticinduced hyperprolactinemia. American Journal of Psychiatry. 1998 Oct 1;155(10):1458-

11. Paleacu D, Barak Y, Mirecky I, Mazeh D. Quetiapine treatment for behavioural and psychological symptoms of dementia in Alzheimer's disease patients: a 6- week, doubleblind, placebo- controlled study. International Journal of Geriatric Psychiatry: A journal of the psychiatry of late life and allied sciences. 2008 Apr;23(4):393-400.

12. Feret BM, Caley CF. Possible hypothyroidism associated with quetiapine. Annals of Pharmacotherapy. 2000 Apr;34(4):483-6.

13. Findling RL, McKenna K, Earley WR, Stankowski J, Pathak S. Efficacy and safety of quetiapine in adolescents with schizophrenia investigated in a 6week, double-blind, placebo-controlled trial. Journal of child and adolescent psychopharmacology. 2012 Oct 1;22(5):327-42. 